\section{New Synthetic Methodology for Regio- and Stereoselective Synthesis of Oligosaccharides via Sugar Ortho Ester Intermediates}

\section{Wei Wang and Fanzuo Kong*}

Research Center for Eco-Environmental Sciences, Academia Sinica, P.O. Box 2871, Bejing 100085, China

\section{Received J une 15, 1998}

Great effort has been devoted to the development of new strategies for glycosidic coupling owing to the growing importance of synthetic ol igosaccharides in glycobi ol ogy. ${ }^{1}$ In the past decades, methods for construction of glycosidic linkages have progressed considerably. ${ }^{2}$ However, compared to the synthesis of oligopeptides and oligonucleotides, the synthesis of oligosaccharides is still laborious work. The use of unprotected or partially protected sugars in glycosidic coupling is of particular interest since synthetic routes can be substantially simplified. In addition, chemistry on unprotected sugars represents a great challenge, as there are only tiny differences in coupling sugar hydroxyl groups, particularly secondary hydroxyl groups.

Formation of sugar-sugar ortho esters in glycosylation is well-known, and these ortho esters are obtained in variable yields, ${ }^{3 a-i}$ sometimes as byproducts, ${ }^{3 j}$ but there have been no reports dealing with the preparation of ortho esters using unprotected or partially protected glycosides as the glycosyl acceptors. In addition, TMSOTf-promoted rearrangement ${ }^{4}$ has only been used to treat fully protected ortho esters formed from reaction with either the primary $4 a, b$ hydroxyl group of a sugar acceptor or a simple aglycon alcohol.4c We now report a new methodology for highly regio- and stereosel ective synthesis of oligosaccharides. That is, (1) the preparation of sugar-sugar ortho esters by coupling acetobromosugars with unprotected alkyl glycosides or partially protected sugar acceptors in high yields and excellent selectivity and (2) the rearrangement of either partially protected or fully protected ortho esters of diverse structure by the catalytic use of TMSOTf.

(1) (a) Dwek, R. A. Chem. Rev. 1996, 96, 683. (b) Synthetic Oligosaccharides. Indispensable Probes for the Life Sciences; Kovac, P., Ed.; ACS Symposium Series 560; American Chemical Society, Washington, DC, 1994

(2) General reviews: (a) PreparativeCarbohydrateChemistry; Hanessian S., Ed.; Marcel Dekker Inc.: New York, 1997; Chapters 12-22. (b) Barresi, F.; Hindsgaul, O. J . Carbohydr. Chem. 1995, 14, 1043. (c) Schmidt, R. R.; Kinzy, W. Adv. Carbohydr. Chem. Biochem. 1994, 50, 21. (d) Toshima, K. Tatsuta, K. Chem. Rev. 1993, 93, 1503. Glycal donors: Dannishefsky, S J.; Bilodeau, M. T. Angew. Chem., Int. Ed. Engl. 1996, 35, 1380. Glycosyl sulfoxide donors: Yan, L.; Kahne, D. J . Am. Chem. Soc. 1996, 118, 9239. 1-Hydroxy glycosyl donors: Garcia, B. A.; Poole, J. A.; Gin, D. Y. J . Am Chem. Soc. 1997, 119, 7597. 1,2-Anhyrdo glycosyl donors: Du, Y.; Kong, F. Tetrahedron Lett. 1995, 427.

(3) (a) Modern Methods in CarbohydrateSynthesis; Khan, S. H., O'Neil, R. A., Eds.; Harwood Academic Publishers: United States, 1996; p 125. (b) Ernst, B.; De Mesmaeker, A.; Wagner, B.; Winkler, T. Tetrahedron Lett. 1990, 6167. (c) Banoub, J.; Boullanger, P.; Potier, M.; Descotes, G. Tetrahedron Lett. 1986, 4145. (d) Dahlin, B. M.; Garegg, P. J .; ohansson, R.; Samuelsson, B.; Orn, U. Acta Chem. Scand. B 1981, 35, 669. (e) Banoub, J .; Bundle, D. R. Can J . Chem. 1979, 57, 2091. (f) Ogawa, T.; Matsui, M Carbohydr. Res. 1976, 51, C13. (g) Zurabyan, S. E.; Tikhomirov, M. M. Nesmeyanov, V. A.; Khorlin, A. Y. Carbohydr. Res. 1973, 26, 117. (h) Wulff, G.; Kruger, W. Carbohydr. Res. 1971, 19, 139. (i) Kochetkov, N. K.; Bochkov, A. F.; Sokolovskaya, T. A.; Snyatkova, V. J . Carbohydr. Res. 1971, 16, 17. (j) Seeberger, P. H.; Eckhardt, M.; Gutteridge, C. E.; Danishefsky, S. J .J. Am. Chem. Soc. 1997, 119, 10064. Kunz, H. Liebigs Ann. Chem. 1986, 717 Kunz, H.; Harreus, A. Liebigs Ann. Chem. 1982, 41. Garegg, P. J .; Konvadsson, P.; K vanstrom, I.; Norberg, T.; Svensson, S. C. T.; Wigilius, B. Acta Chem. Scand. B 1985, 39, 569 .

(4) (a) Gass, J .; Strobl, M.; Kosma, P. Carbohydr. Res. 1993, 244, 69. (b) Sznaidman, M. L.; J ohnson, S. C.; Crasto, C.; Hecht, S. M. J . Org. Chem 1995, 60, 3942. (c) Ogawa, T.; Beppu, K.; Nakabayashi, S. Carbohydr. Res. 1981, 93, C6.
Table 1

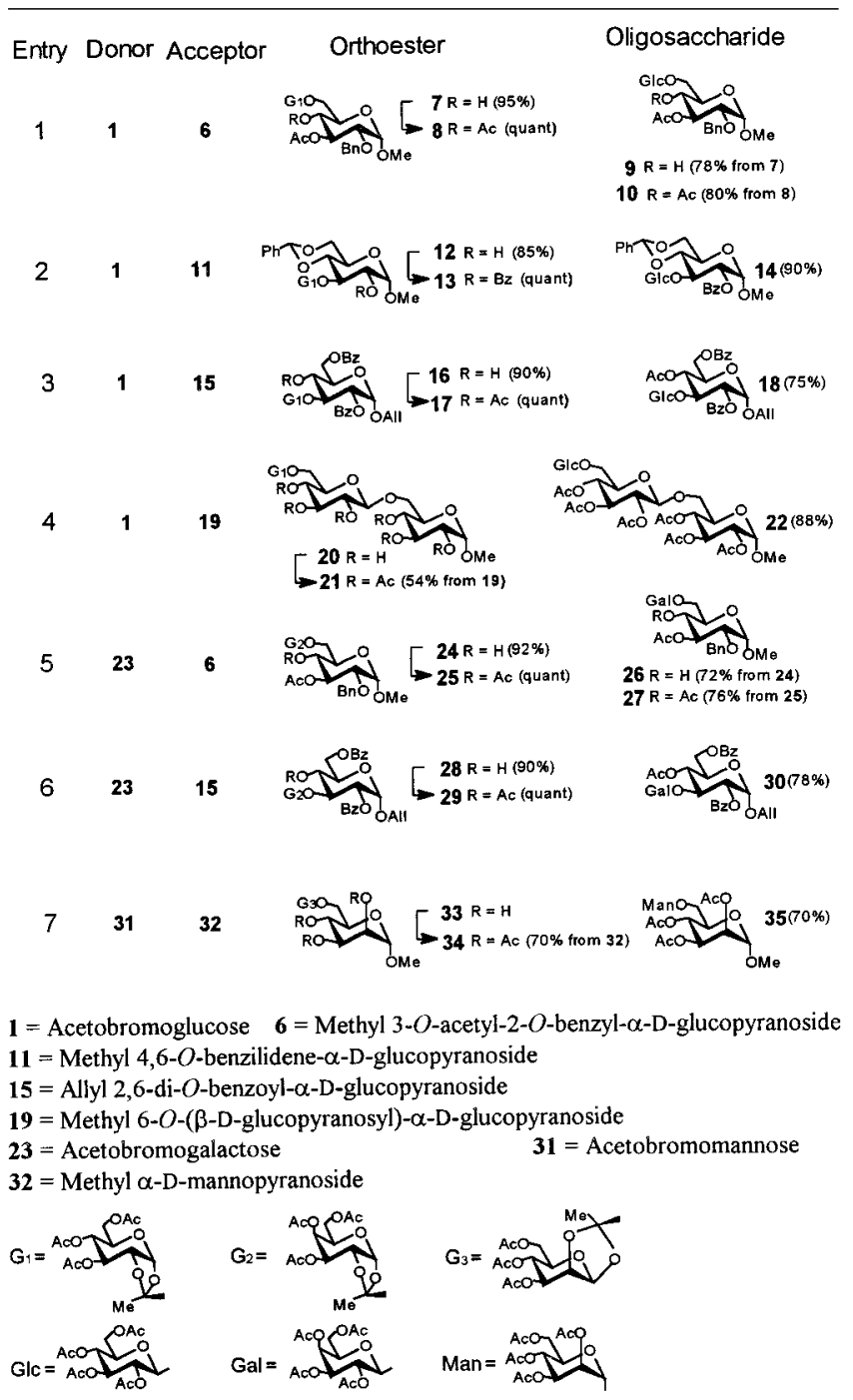

A typical example is presented in entry 1 of Table 1. Coupling $^{5}$ of acetobromoglucose 1 with 4,6-unprotected glucoside 6 promoted by AgOTf in the presence of 2,4lutidine selectively afforded the ortho ester $\mathbf{7}$ in nearly quantitative yield. Rearrangement ${ }^{6}$ of $\mathbf{7}$ with a catalytic amount TMSOTf selectively furnished $\mathbf{9}$ in a satisfactory yield (78\%), and subsequent acetylation gave $\mathbf{1 0}$. To confirm the selectivity of the rearrangement, acetylation of $\mathbf{7}$ (giving 8) followed by rearrangement ( $80 \%)$ gave the same disaccharide 10. The structures $\mathbf{9}$ and $\mathbf{1 0}$ were determined by

(5) Typical conditions for ortho ester preparation: To a stirred mixture of $\mathbf{1}(238 \mathrm{mg}, 0.58 \mathrm{mmol}), \mathbf{6}(188 \mathrm{mg}, 0.577 \mathrm{mmol}), 2,4$-lutidine $(68 \mu \mathrm{L}, 0.58$ $\mathrm{mmol}$ ), and molecular sieves $(0.2 \mathrm{~g})$ in dichloromethane $(6 \mathrm{~mL}$ ) was added silver triflate $(148 \mathrm{mg}, 0.58 \mathrm{mmol}$ ) under nitrogen atmosphere in a dark room, and the reaction was carried out at room temperature and monitored by TLC (2:1 petroleum ether/ethyl acetate). After completion of the reaction, the mixture was partitioned between dichloromethane and water, and the organic phase was concentrated under reduced pressure. The residual oil was purified by silica gel column chromatography with 2:1 petrol eum ether/ ethyl acetate as the eluent, giving the product $\mathbf{7}$ as an amorphous solid in a yield of $95 \%$ (360 mg), capable of being used for further rearrangement.

(6) Typical rearrangement conditions: To a stirred solution of sugarsugar ortho ester $7(360 \mathrm{mg}, 0.55 \mathrm{mmol})$ in dichloromethane $(6 \mathrm{~mL})$ was added TMSOTf (10 $\mu \mathrm{L}, 0.1$ equiv) at $0{ }^{\circ} \mathrm{C}$ under nitrogen atmosphere, and the reaction was monitored by TLC (2:1 petroleum ether/ethyl acetate). After completion of the reaction, to the mixture was added triethylamine $(15 \mu \mathrm{L})$ and then the mixture was treated at the same way as described in (5), giving 9 in a yield of $78 \%$ 


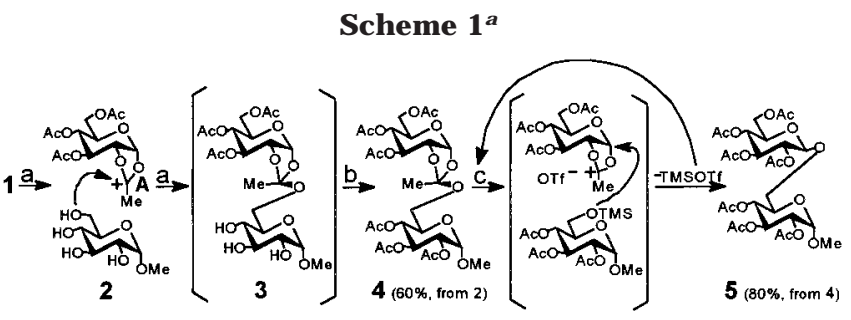

a Key: (a) AgOTf (1 equiv), 2,4-lutidine (1 equiv), DMF, molecular sieves (4A), rt, $\mathrm{N}_{2}, 5 \mathrm{~h}$; (b) Pyr, $\mathrm{Ac}_{2} \mathrm{O}, \mathrm{rt}, 2 \mathrm{~h}$; (c) TMSOTf (0.1 equiv), $\mathrm{CH}_{2} \mathrm{Cl}_{2}$, molecular sieves (4A), $0{ }^{\circ} \mathrm{C}, \mathrm{N}_{2}, 2 \mathrm{~h}$.

${ }^{1} \mathrm{H}$ NMR as described in ref 7. Similar results were obtained for coupling of acetobromogalactose $\mathbf{2 3}$ with the acceptor $\mathbf{6}$ (see entry 5 in Table 1, isolated yields are indicated in parentheses following each product). Again, the rearrangement selectivity was confirmed by the fact that the two paths, i.e., acetylation of $\mathbf{2 4}$ followed by rearrangement of $\mathbf{2 5}$ and rearrangement of $\mathbf{2 4}$ followed by acetylation of $\mathbf{2 6}$, gave the same disaccharide 27 . Exciting results were obtained when this new method was used for the coupling ${ }^{8}$ of acetobromoglycose with unprotected methyl glycosides (see Scheme 1 and Table 1, entries 4 and 7). Coupling of $\mathbf{1}$ with $\mathbf{2}$ gave ortho ester $\mathbf{3}$ as the sole product, and its in situ acetylation (giving 4) followed by rearrangement afforded 1,6- $\beta$-linked disaccharide 5 in a high yield. Coupling of $\mathbf{1}$ with an unprotected 1,6-linked disaccharide 19 followed by rearrangement dramatically furnished 1,6-linked trisaccharide $22 .{ }^{8}$ Excellent regioselectivity for coupling with acceptors having 2,3 or 3,4 free secondary hydroxyl groups was also achieved (see Table 1, entries 2, 3, and 6). It is interesting to note that selective 3-O-glucosylation for either $\mathbf{1 1}$ or $\mathbf{1 5}$ was achieved. This result is different from the reported selective, mercuric bromide promoted 2-O-glucosylation ${ }^{9}$ using 3,4,6-tri-O-acetyl-1,2-O-ethyl orthoacetyl- $\alpha$ -

(7) ${ }^{1} \mathrm{H}$ NMR data for 10: $\delta 4.52\left(\mathrm{~d}, \mathrm{H}-\mathrm{l}^{\prime} \beta\right), 4.63(\mathrm{~d}, \mathrm{H}-1 \alpha), 5.41,5.20$ $5.05,5.01,4.86\left(5 \mathrm{t}, \mathrm{H}-2^{\prime}, 3^{\prime}, 4^{\prime}\right.$, and $\left.\mathrm{H}-3,4\right), 4.67,4.56\left(\mathrm{ABq}, \mathrm{BnCH}_{2}\right), 4.26$ (dd, H-6'a), 4.12 (dd, H-6'b), 3.94-3.44 (m, 4H, H-5,5',6), 3.50 (dd, H-2). ${ }^{1} \mathrm{H}$ NMR data for 9: $\delta 4.58\left(\mathrm{~d}, \mathrm{H}-\mathrm{I}^{\prime} \beta\right), 4.64(\mathrm{~d}, \mathrm{H}-1 \alpha), 5.20(\mathrm{t}, \mathrm{H}-3), 5.18(\mathrm{t}$ $\left.\mathrm{H}-3^{\prime}\right), 5.08$ (t, H-4'), 5.03 (t, H-2'), 4.66, $4.60\left(\mathrm{ABq}, \mathrm{BnCH}_{2}\right), 4.24$ (dd, $\left.\mathrm{H}-6^{\prime} \mathrm{a}\right)$, 4.16 (dd, H-6'b), 4.05 (dd, H-6a), 3.96-3.91 (m, H-5'), 3.78 (dd, H-6b), 3.70$3.66(\mathrm{~m}, \mathrm{H}-5), 3.52(\mathrm{t}, \mathrm{H}-4), 3.48(\mathrm{dd}, \mathrm{H}-2)$

(8) Typical procedure: To a mixture of 2 (108 $\mathrm{mg}, 0.56 \mathrm{mmol}$ ), 2,4-lutidine $(65 \mu \mathrm{L}, 0.56 \mathrm{mmol})$, and molecular sieves $(0.1 \mathrm{~g})$ in DMF $(12 \mathrm{~mL})$ under nitrogen atmosphere was added 1 ( $250 \mathrm{mg}, 0.61 \mathrm{mmol})$ followed by silver triflate ( $145 \mathrm{mg}, 0.56 \mathrm{mmol}$ ). The reaction was carried out in a dark room at room temperature. After being stirred for 5-6 h, the reaction mixture was evaporated under reduced pressure, and pyridine (dry, $1.0 \mathrm{~mL}$ ) and acetic anhydride $(0.8 \mathrm{~mL})$ were added. After $2 \mathrm{~h}$, the reaction mixture was filtered, and the filtrate was washed with aqueous $\mathrm{NaCO}_{3}$ and water and treated the same way as described in (5). The yields of ortho ester with unprotected glycoside acceptors were not very high mainly due to the poor solubility of the acceptors in the reaction medium. ${ }^{1} \mathrm{H}$ NMR data for 5: 5.46, 5.21, 5.08, 5.02, $4.91\left(5 \mathrm{t}, 5 \mathrm{H}, \mathrm{J}=9.6 \mathrm{~Hz}, \mathrm{H}-2^{\prime}, 3,3^{\prime}, 4,4^{\prime}\right), 4.92(\mathrm{~d}, 1 \mathrm{H}$ $\left.\mathrm{J}_{1,2}=3.8 \mathrm{~Hz}, \mathrm{H}-1\right), 4.84(\mathrm{dd}, 1 \mathrm{H}, \mathrm{H}-2), 4.55\left(\mathrm{~d}, 1 \mathrm{H}, \mathrm{J}_{1^{\prime}, \mathrm{z}^{\prime}}=8.0 \mathrm{~Hz}, \mathrm{H}-\mathrm{I}^{\prime}\right)$, 4.28 (dd, $\left.1 \mathrm{H}, \mathrm{H}-6^{\prime} \mathrm{a}\right), 4.13$ (dd, $\left.1 \mathrm{H}, \mathrm{H}-6^{\prime} \mathrm{b}\right), 3.96-3.91$ (m, 2H, H-5',6a), 3.71$3.69(\mathrm{~m}, 1 \mathrm{H}, \mathrm{H}-5), 3.54(\mathrm{dd}, 1 \mathrm{H}, \mathrm{H}-6 \mathrm{~b}), 3.38\left(\mathrm{~s}, 3 \mathrm{H}, \mathrm{CH}_{3}\right), 2.09,2.07,2.05$ $2.03,2.02,2.01,2.00\left(7 \mathrm{~s}, 7 \mathrm{CH}_{3} \mathrm{CO}\right) .{ }^{1} \mathrm{H}$ NMR data for $22: \delta 5.47-4.90(\mathrm{~m}$ $\left.8 \mathrm{H}, \mathrm{H}-1,2^{\prime}, 2^{\prime \prime}, 3,3^{\prime}, 3^{\prime \prime}, 4,4^{\prime}, 4^{\prime \prime}\right), 4.85$ (dd, $\left.1 \mathrm{H}, \mathrm{H}-2\right), 4.58,4.51$ (2d, $\left.2 \mathrm{H}, \mathrm{H}-\mathrm{1}^{\prime}, \mathrm{1}^{\prime \prime}\right)$ $4.30-3.50\left(\mathrm{~m}, 9 \mathrm{H}, \mathrm{H}-5,5^{\prime}, 5^{\prime \prime}, 6,6^{\prime}, 6^{\prime \prime}\right), 3.39$ (s, 3H, $\left.\mathrm{CH}_{3}\right), 2.10,2.07,2.06,2.05$ $2.05,2.04,2.03,2.02,2.00,1.99\left(10 \mathrm{~s}, 30 \mathrm{H}, 10 \mathrm{CH}_{3} \mathrm{CO}\right) .{ }^{1} \mathrm{H} \mathrm{NMR}$ data for 35: $\delta 5.33-5.25\left(\mathrm{~m}, 6 \mathrm{H}, \mathrm{H}-2,2^{\prime}, 3,3^{\prime}, 4,4^{\prime}\right), 4.88,4.70\left(2 \mathrm{~s}, 2 \mathrm{H}, \mathrm{H}-1,1^{\prime}\right), 4.28$ (dd, $\left.1 \mathrm{H}, \mathrm{H}-6^{\prime} \mathrm{a}\right), 4.14$ (dd, $\left.1 \mathrm{H}, \mathrm{H}-6^{\prime} \mathrm{b}\right), 4.12-3.78\left(\mathrm{~m}, 2 \mathrm{H}, \mathrm{H}-5,5^{\prime}\right), 3.80$ (dd, $1 \mathrm{H}, \mathrm{H}-6 \mathrm{a}), 3.58$ (dd, $1 \mathrm{H}, \mathrm{H}-6 \mathrm{~b}), 3.43\left(\mathrm{~s}, 3 \mathrm{H}, \mathrm{CH}_{3}\right), 2.18,2.17,2.13,2.08$ $2.06,2.01,2.00\left(7 \mathrm{~s}, 7 \mathrm{CH}_{3} \mathrm{CO}\right)$
D-glucopyranose as the glucosyl donor and $\mathbf{1 1}$ as the acceptor (the ratio of 2-O-glucosylation to 3-O-glucosylation was 3:1 with a total yield of $28 \%$ ). The selectivity of entry 2 (Table 1) was confirmed by the fact that the disaccharide 14 obtained from the rearrangement of $\mathbf{1 3}$ gave the same ${ }^{1} \mathrm{H}$ NMR data as the reported values. ${ }^{10}$ The sel ectivity of entry 3 (Table 1) was verified by comparison of the disaccharide formed from the rearrangement with an authentic sample, ${ }^{11}$ giving exactly the same ${ }^{1} \mathrm{H} N M R$ data. The ${ }^{1} \mathrm{H}$ NMR data of $\mathbf{3 0}$ showed $\mathrm{H}-4$ at $\delta 5.01$, downfield compared to $\mathrm{H}-3$ ( $\delta$ 4.00-3.88), confirming the 3-0-linkage in entry 6 (Table 1 ).

We rationalize that the high regioselectivity, which cannot be achieved by direct coupling under normal glycosylation conditions, is mainly the result of steric factors, i.e., the attack to the acyloxnium carbon of $\mathbf{A}$ (Scheme 1 ) by less hindered hydroxyl group, while the high regio- and stereoselectivity of the rearrangement results from the C-1 backside attack of $\mathbf{A}$ by the trimethylsilylated acceptor (Scheme 1).

In summary, we have presented a new and very effective method for regio- and stereoselective synthesis of 1,2-translinked oligosaccharides using acetobromoglycose as the glycosyl donor. The high regioselectivity of ortho ester formation can result in a high yield synthesis of $1 \rightarrow 6$ and $1 \rightarrow 3$ linked oligosaccharides, while the high selectivity of rearrangement allows further modification at the unprotected hydroxyl groups of the rearrangement products. This new methodology will be very useful for the synthesis of diand trisaccharides, and in combination with the known methods, synthesis of complex oligosaccharides may be substantially simplified. Further investigation of the application of this new method to the synthesis of complex oligosaccharides is in process.

Acknowledgment. Project 39740022 was supported by the National Natural Science Foundation of China.

Supporting Information Available: ${ }^{1} \mathrm{H}$ NMR data for compounds $\mathbf{4}, \mathbf{7}-\mathbf{1 0}, \mathbf{1 2}, \mathbf{1 3}, \mathbf{1 6}-\mathbf{1 8}, \mathbf{2 1}$, and $\mathbf{2 4 - 3 0}$ (5 pages).

\section{J O981135E}

(9) Kochetkov, N. K.; Khorlin, A. J .; Bochkov, A. F. Tetrahedron 1967 $23,693$.

(10) Takeo, K. Carbohydr. Res. 1979, 75, 245. The reported ${ }^{1} \mathrm{H}$ NMR data of 14: $\delta 8.22-7.25(\mathrm{~m}, 10 \mathrm{H}, \mathrm{Bz}-\mathrm{H}), 5.60(\mathrm{~s}, 1 \mathrm{H}, \mathrm{PhCH}), 3.38\left(\mathrm{~s}, 3 \mathrm{H}, \mathrm{CH}_{3}\right)$ $1.97,1.95,1.88$, and $1.57\left(\mathrm{~s}, 12 \mathrm{H}, 4 \mathrm{CH}_{3} \mathrm{CO}\right) ; \mathrm{mp} 185-186{ }^{\circ} \mathrm{C} ;[\alpha]^{20} \mathrm{D}+35.3^{\circ}$ (c 1.7, $\left.\mathrm{CHCl}_{3}\right)$; Observed: $\delta 8.17-7.27(\mathrm{~m}, 10 \mathrm{H}, \mathrm{Bz}-\mathrm{H}), 5.60(\mathrm{~s}, 1 \mathrm{H}, \mathrm{PhCH})$ 5.16-4.94 (m, 5H, H-1,2, $\left.2^{\prime} 3^{\prime}, 4^{\prime}\right), 4.77\left(\mathrm{~d}, 1 \mathrm{H}, \mathrm{H}-1^{\prime}\right), 4.43-3.56(\mathrm{~m}, 8 \mathrm{H}$ $\left.\mathrm{H}-3,4,5,5^{\prime}, 6,6^{\prime}\right), 3.38\left(\mathrm{~s}, 3 \mathrm{H}, \mathrm{CH}_{3}\right), 1.97,1.95,1.88$, and $1.57\left(4 \mathrm{~s}, 12 \mathrm{H}, 4 \mathrm{CH}_{3-}\right.$ $\mathrm{CO}) ; \mathrm{mp} 184-186{ }^{\circ} \mathrm{C} ;[\alpha]^{16} \mathrm{D}+34.1^{\circ}$ (c 1.2, $\mathrm{CHCl}_{3}$ ). Anal. Calcd for $\mathrm{C}_{35} \mathrm{H}_{40} \mathrm{O}_{16}$ : C, 58.66; $\mathrm{H}, 5.63$. Found: C, 58.76; $\mathrm{H}, 5.62$.

(11) An authentic sample was synthesized for confirming the selectivity of entry 3 of Table 1 as follows. Selective 2-O-benzoylation followed by chloroacetylation of allyl 4,6-O-benzylidene- $\alpha$-D-glucopyranoside gave allyl 4,6-O-benzylidene-2-O-benzoyl-3-O-chloroacetyl- $\alpha$-D-glucopyranoside. Re moval of benzylidene by acidic hydrolysis followed by selective 6-Obenzoylation afforded allyl 2,6-di-O-benzoyl-3-O-chloroacetyl- $\alpha$-D-glucopyranoside. Acetylation followed by dechloroacetylation with thiourea gave the key compound allyl 4-O-acetyl-2,6-di-O-benzoyl- $\alpha$-D-glucopyranoside $\left[[\alpha]^{20} \mathrm{D}+102^{\circ}\left(\mathrm{c} 4.0, \mathrm{CHCl}_{3}\right) ;{ }^{1} \mathrm{H}\right.$ NMR $\delta 8.15-7.40(\mathrm{~m}, 10 \mathrm{H}, \mathrm{Bz}-\mathrm{H}), 5.96-$ $5.74\left(\mathrm{~m}, 1 \mathrm{H}, \mathrm{CH}_{2}=\mathrm{CHCH}_{2}-\right), 5.34-5.09\left(\mathrm{~m}, 4 \mathrm{H}, \mathrm{H}-2,4, \mathrm{CH}_{2}=\mathrm{CHCH}_{2}-\right)$ $5.21\left(\mathrm{~d}, 1 \mathrm{H}, \mathrm{J}_{12}=4.0 \mathrm{~Hz}, \mathrm{H}-1\right), 4.58-3.98\left(\mathrm{~m}, 6 \mathrm{H}, \mathrm{H}-3,5,6, \mathrm{CH}_{2}=\mathrm{CHCH}_{2}-\right.$ ), $2.16\left(\mathrm{~s}, 3 \mathrm{H}, \mathrm{CH}_{3} \mathrm{CO}\right.$ ). Anal. Calcd for $\mathrm{C}_{25} \mathrm{H}_{26} \mathrm{O}_{9}$ : C, 63.76; $\mathrm{H}, 5.60$. F ound: C. 63.82; H, 5.58], the direct coupling of which with acetobromoglucose in the presence of AgOTf furnished allyl 4-O-acetyl-3-O-(2,3,4,6-tetra-O-acetyl$\beta$-D-glucopyranosyl)-2,6-di-O-benzoyl- $\alpha$-D-glucopyranoside (18), identical with the product obtained from rearrangement of $\mathbf{1 7}$ 